\title{
The Mission Itself is in Question
}

\author{
Diana Brydon \\ University of Manitoba
}

\begin{abstract}
A the Postcolonial," I got asked a question that momentarily stumped me: "Your paper is interesting," the questioner said, "but what is postcolonial about it?" Having entered the field before it was named, I had not anticipated that it would become a category that would limit the original thrust of my engagement in ways that closed off inquiries that to my mind, at least, began from the postcolonial but led into interdisciplinary and globalizing fields. At first, the question struck me as irrelevant. Does it matter what we call it as long as it matters? If this is where postcolonial inquiry is leading me, then surely it is relevant to reroutings of the postcolonial? But as I thought more deeply about what the question implied, it began to resonate for me with the theme of this forum's topic: "Why do I have to write like that?" If I was engaging the field at all, it was not in a manner immediately recognizable to practitioners who came with a certain set of expectations about what postcolonial work can do. There will always be consequences for how we choose to write. There is always a tendency toward ossification in institutionalization, but it is usually balanced, in our system, by demands for the new. If our questions and inquiries do not match the needs of any clearly defined audience, then we may have trouble
\end{abstract}

ESC 32.2-3 (June/September 2006): 28-31 
getting our work published or read. But if we write about what matters to us in a way true to its complexities and the challenges it poses for us, I think we will find readers who wish to participate in that quest.

There is now an established audience for postcolonial work in literary studies, but the field has lost its urgency. In that sense, it shares the larger malaise that has seized English studies as a whole. Postcolonial criticism seems to have entered a phase in which the insights it can generate have become predictable. Stephen Slemon's question implies that our times, and our needs in these times, require writing that poses its questions differently. Writing we once found compelling now leaves us cold. If teaching is indeed about the "uncoercive rearrangement of desires" (Chakravorty 41), as Gayatri Spivak has famously suggested, then how are our desires being rearranged at the current moment? Can we any longer distinguish between the coercive and the uncoercive in shaping what we currently desire to read and write? This is not about intellectual fashion but about what matters to literary scholars today. I moved into Commonwealth and then postcolonial studies in search of literary engagements beyond those centred on Britain and the United States. (Even Canadian literature was not offered as part of an English degree when I did my BA.) Postcolonial studies enabled me to engage with writing from many more different parts of the world, and those engagements forced reconsideration of the canon, questions of value, the inter-relations of text and world, and the role of colonialism in the institutions that governed most aspects of everyday life in formerly colonized countries and the ex-empires that had once ruled them. In other words, it led beyond literary studies into other realms of inquiry and different ways of writing. I have become one of those people who read less literary criticism and more of the work generated by a range of disciplinary and interdisciplinary inquiry. My questions cross the lines still demarcated by the arrangement of our disciplines in the university today.

With globalization, the former autonomy of cultural, social, economic, and political realms is thrown into question in ways that force scholars to rethink how they frame their work and how they communicate their questions and their findings. In an article titled "After Post-Colonialism," David Carter argues that our current conjuncture poses "a more radical challenge to literary scholars than the textual politics of transgressive reading" (117). Our times, he suggests, demand "a new cross-disciplinary approach that we've only just begun to invent" (117). That re-invention requires a differently oriented type of self-scrutiny than the one we have practised to date: Who do we write for and why? What are we trying to

\author{
DIANA BRYDON is \\ Canada Research Chair \\ for Globalization and \\ Cultural Studies and \\ Director of the Research \\ Centre for Globalization \\ and Cultural Studies \\ at the University of \\ Manitoba. Her current \\ research examines the \\ cluster of meanings \\ attached to concepts \\ of home under the \\ pressures of globalizing \\ processes within the \\ contexts of postcolonial \\ cultural studies and \\ discourses around \\ globalization.
}


Nonetheless, as

literary schol-

ars, we need to

supplement our

protests that

current modes

of measurement

do not serve us

well by thinking

very hard about

alternative

measures that

might match

what we value

most about the

work we do and

hope to do. achieve through our writing? If we are teaching, what do our students need to learn, how best can we teach them and measure their success?

To move toward such re-invention requires forms of unlearning as well as learning. Such work (as Carter notes) is best described as posttheory rather than anti-theory. It requires greater intellectual depth, not dumbing-down, to try to stand outside the changing pressures of our current moment while fully engaging the new challenges that it sets us. It has become commonplace to insist on the need to move beyond the single-authored thesis or book, yet this requirement is becoming more entrenched institutionally at the very moment we are recognizing its increasing irrelevance. That is partly because it seems an easy measurement of achievement at a time when measuring achievement has become a requirement for advancement. We have no such easy measures for assessing the kinds of team-based, interdisciplinary research that better meet our current needs. Perhaps few of us are qualified, as individuals, for taking on such tasks. Nonetheless, as literary scholars, we need to supplement our protests that current modes of measurement do not serve us well by thinking very hard about alternative measures that might match what we value most about the work we do and hope to do. At a recent workshop on academic journals, I was interested to learn that Interventions does not usually, as a rule, review multi-authored texts. Such a rule needs to be made more flexible, distinguishing between the kind of miscellany often produced hastily by conferences and the more sustained kind of team reflection produced through more long-term, collaborative research. Learning to work co-operatively with scholars from other disciplines can compel us to unpack our assumptions and the language that often hides them from us in ways that may help us to write again in ways that satisfy our own deepest needs. To open the conversation about the institutional structures within which we work and how they might best enable the kind of work that we would like to see produced, we need to expand our range beyond privileging the research-teaching continuum above the "service" that enables, adjudicates, or blocks that work. It is not "professionalization" we need so much as a renewed attention to our roles within the interlocking relations on which academic writing, reading, and assessment depend and the ways in which they are currently threatened. It is no longer just a question of renewing the language. The mission itself is in question. 


\section{Works Cited}

Carter, David. "After Post-Colonialism." Meanjin ("On Globalisation and Postcolonial Culture") 66.2 (2007): 114-19.

Chakravorty, Swapan, Suzana Milevska, and Tani E. Barlow. "Home." Conversations with Gayatri Chakravorty Spivak. London: Seagull, 2006. 1-55. 